\title{
Um estudo sobre segurança em estádios de futebol baseado na análise bibliométrica da literatura internacional
}

\section{Leonardo Ensslin}

\author{
Engenheiro Mecânico (UFRGS).Mestre em \\ Engenharia de Produção (UFSC).Ph.D. em \\ Engenharia Industrial e Sistemas (Univ. of \\ Southern California). Pós-Doutorado em \\ Management Science (Univ. of Lancaster). \\ Professor Titular do Departamento de Engenharia \\ de Produção (EPS) da Universidade Federal de \\ Santa Catarina (UFSC)
}

Sandra Rolim Ensslin

Graduada em Ciência Contábeis pela UCPEL(1991). Mestre em Engenharia de Produção pela UFSC (1995).Doutora em Engenharia de Produção pela UFSC (2002). Professora Associada do Departamento de Ciências Contábeis da Universidade Federal de Santa Catarina (UFSC)

Giovanni Cardoso Pacheco

Especialista em Gestão da Qualidade no Serviço Público pela ESAG/UDESC (2000) e em Prevenção ao Crime pela UNISUL (2003). Mestrando do Programa de Pós-Graduação em Engenharia de Produção da UFSC

No Brasil e em diversos países do mundo, o futebol, mais do que competição ou profissão, se constitui em uma atividade lúdica, de festa e entretenimento. No futebol, diferentemente do que ocorre em outras manifestações culturais, a participação das pessoas está impregnada de paixão, que, se por um lado faz o espetáculo ainda mais grandioso, quando canalizada para expressar alegria, pode, ainda, causar violência e destruição. Atualmente, o aumento da violência em estádios de futebol tem gerado significativa preocupação às autoridades, em especial às forças policiais, envolvidas em empreender ações no sentido de reduzir os riscos; porém o processo carece de cientificidade. $O$ objetivo deste artigo de natureza exploratória-descritiva é construir nos pesquisadores, o conhecimento acerca do tema, por meio da Análise Bibliométrica da literatura internacional, utilizando o 
processo Knowledge Development Process Constructivist (ProKnow-C). Para tal foram pesquisados artigos publicados entre 2001 e 2010 em periódicos científicos disponíveis no portal da CAPES. Os 14 artigos com reconhecimento científico, alinhados com a visão dos pesquisadores sobre o tema "Gestão de Riscos em Estádios de Futebol, que compõem o Portfólio Bibliográfico foram analisados com o propósito de identificar: os periódicos, artigos, autores e palavraschave de destaque. Conclui-se que o processo utilizado propiciou aos pesquisadores o conhecimento do estado da arte sobre o tema, oportunizando a continuidade das pesquisas.

Palavras-chave: Avaliação de desempenho; Gestão de risco; Decisão; Análise Bibliométrica; Futebol; Esporte.

\section{A study about safety in football stadiums based on bibliometric analysis of international literature}

In Brazil and in many countries around the world, soccer, in addition to being a competition or professional activity, has been considered a leisure activity and entertainment. In soccer matches, different to what happens in other cultural events, there is a passionate participation of people. If, in one hand, this makes the spectacle even greater, with expression of joy, it could, on the other hand, also cause violence and destruction. Currently, the increase of violence in football stadiums has generated significant concern to the authorities, especially police forces, involved in undertaking actions to reduce risks during soccer matches. However, this process lacks scientific grounds. The aim of this exploratory and descriptive paper is to build up knowledge about the theme for researchers through the bibliometric analysis of international literature, by using the Proknow-C process (Knowledge Development Process - Constructivist). We searched articles published between 2001 and 2010 in scientific journals available on the CAPES website. The research resulted in a Bibliographic Portfolio composed by 14 scientifically sound articles, aligned with the researchers view on the theme "Risk management in soccer stadiums". These articles were analyzed to identify: the main journals, articles, authors and 
keywords. It is concluded that the process used has provided the researchers with the knowledge of the state of the art on the theme, allowing the continuation of the research.

Keywords: Performance evaluation; Risk management; Decision; Bibliometric analysis; Soccer; Sport.

Recebido em 31.07.2011 Aceito em 23.04.2012

\section{Introdução}

Quem, morando nas grandes cidades, nunca se deparou com ruidosos e inflamados grupos de torcedores circulando a pé pelas ruas, ou em carreatas, ou de ônibus, com suas camisas e bandeiras coloridas, fazendo barulho, saudando os seus iguais ou provocando os adversários?

No Brasil e em diversos países do mundo, o futebol, muito mais do que competição ou profissão, se constitui em uma atividade lúdica, de festa e entretenimento. No futebol, diferentemente do que ocorre em outras manifestações culturais, a participação das pessoas está impregnada de paixão, que, se por um lado faz o espetáculo ainda mais grandioso, quando canalizada para expressar alegria, pode, ainda, por outro lado, causar violência e destruição.

A violência no futebol não é acontecimento novo e há exemplos na história do futebol brasileiro e mundial (MURPHY; WILLIAMS; DUNNING, 1994) de atos de extrema violência entre torcedores. Casos como os dos estádios de São Januário (Rio de Janeiro - final do campeonato brasileiro de futebol de 2000), Morumbi (São Paulo - final da taça São Paulo de Futebol Júnior) e Pacaembú (São Paulo - jogo Corinthians e River Plate válido pela Taça Libertadores da América) são alguns exemplos de tragédias que aconteceram em decorrência de atos violentos ocorridos em estádios de futebol, resultando, em todos os casos, na morte de pessoas. $\mathrm{Na}$ literatura internacional, é possível encontrar diversos relatos acadêmicos e jornalísticos sobre os desastres de Hillsborough (Inglaterra 1989) e Heysel (Bélgica - 1985), que resultaram na morte de diversas pessoas (96 em Hillborough e 39 em Heysel). Essas tragédias serviram de base para estudos de diversos pesquisadores acerca do tema da violência em estádios de futebol, estudos estes que culminaram em mudanças nas normas de segurança dos estádios e nas legislações penais de alguns países, em especial na Inglaterra. Johnes (2004, p. 314) afirma que: "durante o século XX, 276 pessoas perderam a vida em desastres nos campos de futebol do Reino Unido".

Estudo realizado por Reis (2005) aponta questões culturais e estruturais dentre as principais causas da violência em estádios no Brasil. Dentre estas causas está a falta de condições estruturais de segurança nos estádios brasileiros. 
Some-se às informações anteriormente apresentadas o fato de que os estádios de futebol brasileiros são instalações esportivas, cujas estruturas físicas foram dimensionadas para um contexto diferente e menos complexo, em termos de necessidade de segurança, daquele encontrado atualmente nos eventos esportivos que sediam jogos importantes. Uma rápida análise sobre as datas de inauguração dos 40 estádios de futebol brasileiros, utilizados entre 2003 e 2011 para a disputa do Campeonato Brasileiro da Série A, evidencia que $87 \%$ dos estádios brasileiros foram construídos antes de 1989, ou seja, há mais de 20 anos, conforme apresentado na Tabela 1.

Tabela 1 - Distribuição dos estádios brasileiros utilizados no Campeonato Brasileiro da Série A entre 2003 e 2011, por ano de construção

\begin{tabular}{|c|c|c|c|}
\hline Ano de construção & Quantidade & $\%$ & $\sum \%$ \\
\hline Entre 1910 e 1919 & 1 & $3 \%$ & $3 \%$ \\
\hline Entre 1920 e 1929 & 1 & $3 \%$ & $6 \%$ \\
\hline Entre 1930 e 1939 & 4 & $10 \%$ & $16 \%$ \\
\hline Entre 1940 e 1949 & 5 & $12 \%$ & $28 \%$ \\
\hline Entre 1950 e 1959 & 6 & $15 \%$ & $43 \%$ \\
\hline Entre 1960 e 1969 & 4 & $10 \%$ & $53 \%$ \\
\hline Entre 1970 e 1979 & 9 & $22 \%$ & $75 \%$ \\
\hline Entre 1980 e 1989 & 5 & $12 \%$ & $87 \%$ \\
\hline Entre 1990 e 1999 & 1 & $3 \%$ & $90 \%$ \\
\hline Entre 2000 e 2009 & 4 & $10 \%$ & $100 \%$ \\
\hline Total & 40 & $100 \%$ & \\
\hline
\end{tabular}

Fonte: Autores (2011).

Essa situação tem resultado em insegurança para as pessoas que frequentam os estádios de futebol, sejam elas atletas, árbitros, dirigentes, profissionais de imprensa ou torcedores. Atos de violência têm ocorrido com relativa frequência, não apenas no interior dos estádios como, também, em seu entorno, fruto do confronto entre torcedores.

Atualmente, o aumento da violência em estádios de futebol tem gerado significativa preocupação às autoridades, em especial às forças policiais, envolvidas em empreender ações no sentido de reduzir os riscos, que podem propiciar atos de violência ou causar ferimentos às pessoas, em caso de tumulto ou pânico.

Com a escolha do Brasil para sede da Copa do Mundo de Futebol de 2014, estão sendo realizadas diversas ações, dentre as quais cabe destacar uma nova normatização para a avaliação das condições físicas dos estádios de futebol e a punição de pessoas que venham a cometer atos de violência e desordem no interior ou nos arredores dos estádios.

Dentre as principais ações de caráter preventivo empreendidas pelas forças policiais, a fim de reduzir os riscos presentes nos estádios de futebol e em seu entorno, está a realização das vistorias preventivas nos estádios, ocorridas antes de cada campeonato e, a título de manutenção, 
antes de cada um dos jogos. O problema é que, embora haja normatização federal orientando a realização de tais vistorias, a escolha dos critérios e o processo de realização carecem de cientificidade. Essa lacuna permite afirmar que existe a necessidade de se estabelecer um processo com reconhecimento científico, para avaliar os riscos inerentes à segurança nos estádios de futebol. Ou seja, há necessidade de se estabelecer um processo cientificamente reconhecido para avaliar as instalações físicas dos estádios, identificando os riscos inerentes à segurança, a fim de que possam ser eliminados ou minimizados.

Decker (2001, p. 1) define gestão de risco como sendo "um processo sistemático e analítico que considera a probabilidade de uma ameaça pôr em perigo um bem, indivíduo, ou função e identifica ações para reduzir o risco e mitigar as conseqüências de um evento". O processo de avaliação de risco é uma forma de determinar níveis de risco e ameaças, além de permitir a identificação de vulnerabilidades (HALL et al., 2007).

A gestão de riscos relativos à segurança nos estádios de futebol, para efeito desta pesquisa, terá em conta dois aspectos: os riscos inerentes à parte física dos estádios de futebol e os riscos inerentes ao controle de multidões. As ações para reduzir os riscos ou mitigar as consequências são as mais variadas. Hall et al. (2007) destacam: a implementação de controles de acesso; a utilização de câmeras de segurança (CFTV); melhorias na iluminação; incentivo à verificação de antecedentes; credenciamento de torcedores; verificação de mochilas; melhoria das redes de comunicação; e o desenvolvimento e atualização de resposta de emergência e planos de evacuação.

Tendo em vista a complexidade, confusão, interesses conflitantes e incertezas envolvidos em tal contexto, será utilizada a seguinte definição de "avaliação de desempenho", como parte integrante da percepção dos pesquisadores sobre o tema. Avaliação de Desempenho é o processo de gestão utilizado para construir, fixar e disseminar conhecimentos por meio da identificação, organização, mensuração e integração dos aspectos necessários e suficientes para medir e gerenciar o desempenho dos objetivos estratégicos de um determinado contexto da organização, segundo os valores e preferências do gestor (ENSSLIN et al., 2007; IGARASHI, PALADINI, ENSSLIN. 2007; ZANCOPE et al., 2010; ENSSLIN et al, 2010b, BORTOLUZZI et al., 2011). Com essa visão de mundo em mente, o propósito da análise de risco será visto como o método de fornecer suporte à decisão da segurança em um estádio de futebol (AVEN, 2007).

Nestes termos, para o tema relacionado com a avaliação de risco, voltado para a segurança em estádios de futebol profissional, sob a ótica de seu desempenho, o pesquisador busca responder as perguntas: i) Quais os artigos mais relevantes acerca da avaliação de risco relacionada a estádios de futebol profissional?; e ii) Quais os mais destacados artigos, autores, periódicos e palavras-chave, sobre este tema? 
Como resposta a essas perguntas, o presente trabalho tem como objetivo construir conhecimento, nos pesquisadores, para criar as condições para que os mesmos, em um segundo momento, tenham condições de dar continuidade à presente pesquisa, nas atividades de identificação de oportunidades (lacunas) de investigação em seu tema de interesse, "Gestão de Riscos em Estádios de Futebol". O conhecimento a ser construído nesta pesquisa será constituído pela: i) evidenciação de um conjunto de artigos (portfólio bibliográfico) com reconhecimento científico, alinhados com a visão do pesquisador sobre o tema "Gestão de Riscos em Estádios de Futebol"; e ii) evidenciação dos artigos do portfólio bibliográfico de maior destaque, quais os periódicos que mais publicaram, quais os autores de maior destaque e as palavras-chaves mais utilizadas.

Por fim, esse artigo se apresenta em cinco seções: (i) introdução; (ii) metodologia; (iii) instrumento de intervenção, pelo qual são expostos os procedimentos para formar o Portfólio Bibliográfico; e (iv) considerações finais.

\section{Metodologia}

O objetivo desta seção será apresentar os procedimentos metodológicos utilizados para delinear e executar a pesquisa, a fim de atingir os objetivos e resultados finais.

No enquadramento metodológico, foram definidos: i) o objetivo da pesquisa; ii) a lógica da pesquisa; iii) o processo da pesquisa; iv) o resultado da pesquisa; v) os procedimentos técnicos; e vi) o instrumento a ser utilizado na pesquisa.

A natureza da presente pesquisa, quanto ao objetivo, é do tipo exploratória-descritiva: exploratória, pois pretende construir no pesquisador o conhecimento acerca do tema, por meio do processo de seleção e análise dos artigos científicos - ProKnow-C - publicados em periódicos (VIEIRA, 2002); descritiva, pois descreve as características dos artigos que compõem o Portfólio Bibliográfico, em termos dos periódicos que mais publicaram sobre o tema, dos artigos com maior reconhecimento científico, dos autores de maior destaque e das palavras-chaves mais utilizadas. (GIL, 1999).

No que se refere à natureza do artigo, a pesquisa classifica-se como teórica ilustrativa (ALAVI e CARLSON, 1992), pois busca consolidar informações da literatura sobre o problema da avaliação de risco na segurança de estádios de futebol, agregando um caso prático de aplicação do processo de análise bibliométrica (FERREIRA; YOSHIDA, 2004).

Quanto à sua lógica, a pesquisa é indutiva, posto que gera conhecimento acerca de um tema de pesquisa ainda não muito desenvolvido (IUDÍCIBUS, 2004). A geração do conhecimento ocorre pela seleção do Portfólio Bibliográfico, por meio da identificação dos artigos mais alinhados com a visão de mundo dos autores $e$, também, pela identificação dos artigos, periódicos, autores e palavras-chave mais destacados dentro do Portfólio Bibliográfico. 
A coleta de dados, dentro do processo de pesquisa, levará em conta os dados primários e os dados secundários. Os dados primários advêm das delimitações estabelecidas pelos autores/pesquisadores ao longo do processo de seleção do Portfólio Bibliográfico. Os dados secundários são obtidos em decorrência dos resultados das análises dos artigos do Portfólio Bibliográfico e das referências constantes dos artigos do Portfólio Bibliográfico (RICHARDSON, 1999). Quanto à abordagem do problema, o trabalho pode ser enquadrado como qualitativo e quantitativo, ao mesmo tempo. A abordagem qualitativa fica evidenciada no subprocesso de seleção dos artigos que irão compor o Portfólio Bibliográfico. A abordagem quantitativa fica evidenciada no subprocesso de análise bibliométrica (RICHARDSON, 1999).

Quanto ao seu resultado, a pesquisa é do tipo aplicada, pois é possível utilizar os conhecimentos gerados e direcionar o estudo para os artigos, autores e periódicos considerados relevantes na análise bibliométrica (LAKATUS; MARCONI, 2006).

No que se refere aos procedimentos técnicos, a pesquisa é do tipo bibliográfica, pois foi realizada a partir da análise de publicações científicas, revisadas e indexadas nas bases de dados disponibilizadas pela Coordenação de Aperfeiçoamento de Pessoal de Nível Superior (CAPES) (SÁ-SILVA; ALMEIDA; GUINDANI, 2009). A pesquisa ainda pode ser enquadrada com pesquisa-ação, pois, como afirma Gil (1999), o pesquisador interage durante todo o processo com o objeto da pesquisa.

Quanto ao instrumento de intervenção, foi utilizado o processo de revisão bibliográfica denominado Knowledge Development Process Construtivist (ProKnow-C) proposto por Ensslin et al. (2010a), que, sob a ótica construtivista, apresenta um processo estruturado para construir, no pesquisador, o conhecimento necessário para iniciar a pesquisa acerca do tema que deseja investigar. A Figura 1 representa esquematicamente o enquadramento metodológico da pesquisa.

Figura 1 - Enquadramento metodológico da pesquisa

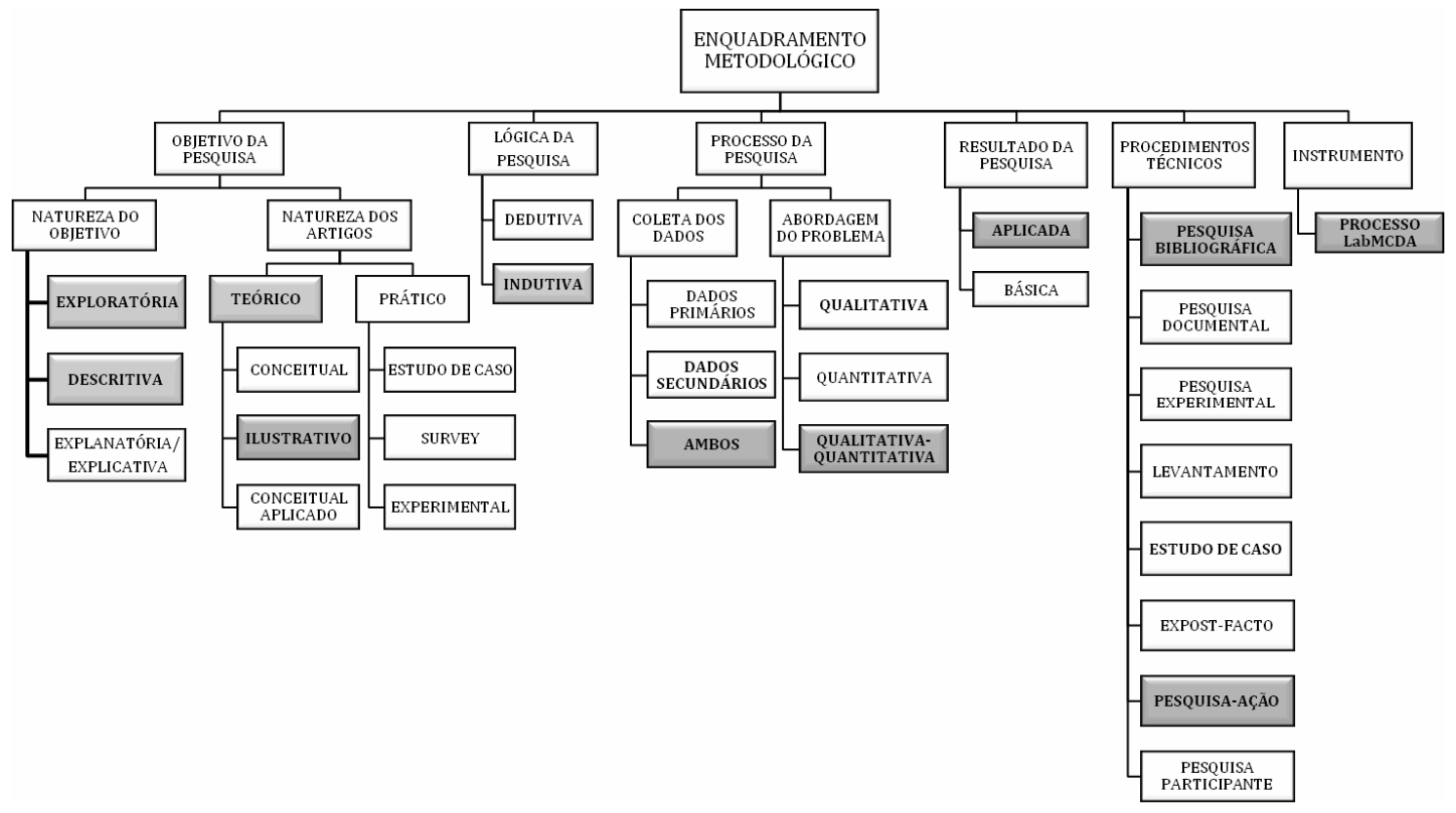


Fonte: adaptado de ENSSLIN (2011).

\section{Instrumento de intervenção}

A construção do conhecimento necessário para iniciar uma pesquisa, segundo Ensslin et al. (2010a) e Ensslin (2011), apresenta singularidade em relação ao pesquisador e as delimitações por ele definidas para a pesquisa, e é influenciada pelo contexto onde o pesquisador está inserido e pela disponibilidade de acesso aos meios de divulgação de pesquisas. Devido à abundante disponibilidade de conhecimentos e informações disponíveis na literatura internacional, dispersos em uma grande variedade de fontes de pesquisa, a realização de pesquisa científica se tornou muito complexa (TASCA et al., 2010; AZEVEDO et al., 2011; ROSA et al, 2011; LACERDA et al., 2012; ROSA et al., 2012).

Desta complexidade, emerge a necessidade de utilização de um processo estruturado que possa orientar o pesquisador na seleção dos estudos mais relevantes do ponto de vista acadêmico, dentro do contexto do estudo que se propôs realizar, formando, assim, um sólido quadro teórico que permita justificar suas escolhas (TASCA et al., 2010; AFONSO et al., 2011; AZEVEDO et al., 2011; ROSA et al, 2011; LACERDA et al., 2012; ROSA et al., 2012).

No presente estudo, foi escolhido o processo ProKnow-C, proposto por Ensslin et al., (2010a), como instrumento de intervenção (AFONSO et al., 2011; BORTOLUZZI et al., 2011; LACERDA, ENSSLIN, ENSSLIN, 2012). O processo ProKnow-C é composto por quatro etapas: i) seleção de um portfólio de artigos sobre o tema da pesquisa; ii) análise bibliométrica do portfólio; iii) análise sistêmica; e iv) definição da pergunta de pesquisa e objetivo de pesquisa.

Figura 2 - Macroetapas do processo de Revisão Sistêmica, com destaque para as etapas utilizadas na presente pesquisa

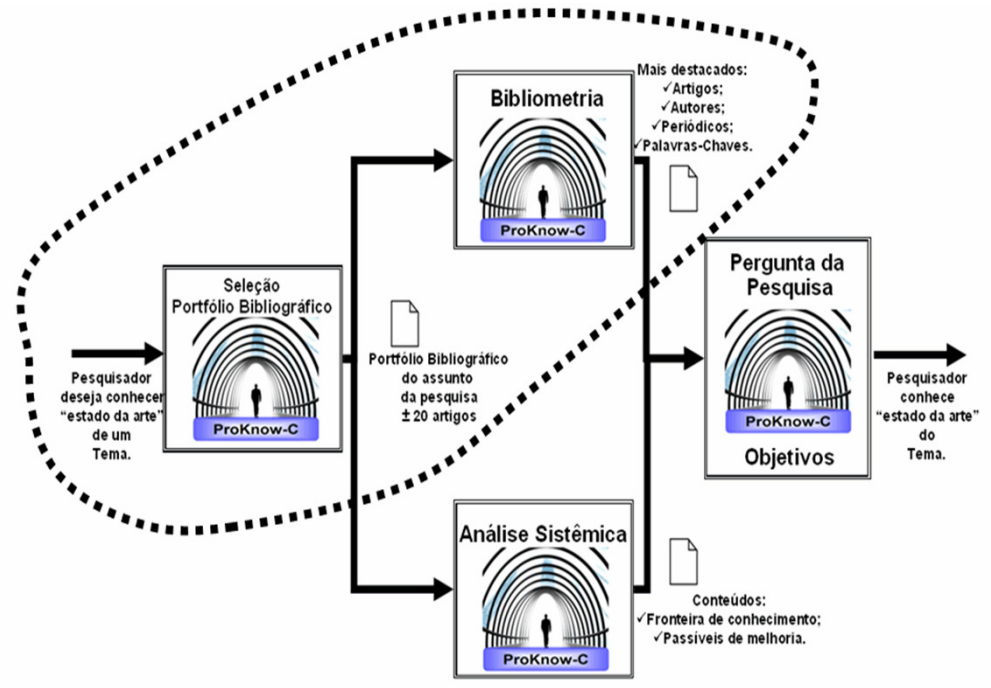

Fonte: ENSSLIN et al. (2010a). 
Para fins desta pesquisa, serão aplicadas apenas duas etapas da metodologia: a seleção de um portfólio de artigos sobre o tema da pesquisa e a análise bibliométrica do portfólio. Desta forma, será construída apenas parte do conhecimento necessário acerca do tema pesquisado. A Figura 2 apresenta, em destaque, as etapas da metodologia que serão aplicadas no presente artigo.

\subsection{Seleção do Portfólio Bibliográfico}

O subprocesso de seleção do portfólio de artigos permite selecionar um Portfólio Bibliográfico, composto pelos artigos considerados mais relevantes na área de conhecimento relativa ao tema da pesquisa, alinhados com a percepção do pesquisador, alinhamento este representado pelas delimitações que o pesquisador estabelece para a pesquisa. O subprocesso de seleção do portfólio de artigos é desenvolvido através de duas etapas: i) a seleção dos artigos nas bases de dados, compondo o Banco de Artigos Brutos; e ii) a filtragem dos artigos selecionados com base no alinhamento com o tema da pesquisa. $O$ resultado do subprocesso de seleção do portfólio de artigos é um conjunto de artigos considerados relevantes pelo pesquisador e que estejam alinhados com o tema da pesquisa. Este conjunto de artigos é denominado Portfólio Bibliográfico (ENSSLIN et al., 2010a; AFONSO et al., 2011; BORTOLUZZI et al., 2011; LACERDA, ENSSLIN, ENSSLIN, 2012).

\subsubsection{Seleção do Banco de Artigos Brutos}

O ponto de partida da etapa de Seleção do Banco de Artigos Brutos é a definição dos eixos de pesquisa, realizada segundo a percepção do pesquisador. Para aplicação do método, foram definidos dois eixos de pesquisa. O primeiro eixo está relacionado ao tema central do trabalho, qual seja, a Gestão de Risco em Estádios de Futebol. O segundo eixo está embasado na necessidade de construir conhecimento no pesquisador acerca do contexto, de tal forma que permita seu monitoramento e aperfeiçoamento. Assim, o segundo eixo trata da Avaliação de Desempenho.

A etapa de Seleção do Banco de Artigos Brutos é composta por quatro fases distintas: definição das palavras-chave; definição dos bancos de dados; busca dos artigos nos bancos de dados com as palavras-chave; e realização de teste de aderência das palavras-chave.

\section{a) definição das palavras-chave:}

Inicialmente foram definidas as palavras-chave para cada um dos eixos da pesquisa: Eixo 1 - Avaliação de Desempenho e Eixo 2 - Gestão de Risco em Estádios de Futebol. Esta ação teve por resultado a definição de quatro palavras-chave para o eixo 1 e seis para o eixo 2. Combinadas as palavras-chave dos eixos da pesquisa, obtêm-se um total de 24 combinações de palavras-chave a serem utilizadas na busca por artigos 
dentro das bases de dados de publicações disponibilizadas pela CAPES. No Eixo 1, foram definidas as seguintes palavras-chave: "PERFORMANCE MEASUREMENT", "PERFORMANCE APPRAISAL", "PERFORMANCE EVALUATION" e "PERFORMANCE ASSESSMENT". No Eixo 2, foram definidas as seguintes palavras-chave: "SPORTS FACILITIES", "RISK MANAGEMENT IN STUDIUMS", "SECURITY STADIUMS", "SPORTS EVENTS SECURITY", "SECURITY EVENTS MANAGEMENT" e "SPORTS RISK ASSESSMENT".

b) definição dos bancos de dados:

Na sequência, buscou-se, entre as bases de dados constantes do Portal de Periódicos da CAPES, aquelas que estavam alinhadas às áreas de conhecimento consideradas pelos autores como relevantes para a pesquisa: Ciências Sociais Aplicadas, Engenharias e Multidisciplinares.

Foram identificadas 124 bases de dados, das quais foram escolhidas 15 bases de dados com potencial para colaborar com artigos, após análise quanto ao alinhamento com o tema da pesquisa. Sobre o conteúdo das 15 bases de dados selecionadas, foi efetuada a busca pelas 24 combinações de palavras-chave, utilizando os campos título (article title), resumo (abstract) e palavra-chave (keywords). Outros critérios estabelecidos para as buscas foram a delimitação temporal de 10 anos (2001 a 2010) e o tipo de publicação (apenas do tipo Journal Article).

As buscas nas bases de dados não retornaram resultados para as combinações de palavras-chave pesquisadas. Foram revisadas as palavras-chave, sendo eliminado o primeiro eixo de pesquisa e mantendo as palavras chave do segundo eixo de, totalizando 6 palavras-chave. Refazendo o processo de pesquisa nas ferramentas de busca das bases de dados, dentro dos mesmos critérios anteriormente definidos (campos de pesquisa, lapso temporal e tipo de publicação) ficou evidenciado que 11 das 15 bases de dados selecionadas retornaram resultados para o novo conjunto de palavras-chave, sendo consideradas com potencial para a pesquisa.

Foram selecionadas para compor o banco de dados de pesquisa as seguintes bases de dados: SCOPUS, EBSCO HOST, ENGENEERING VILLAGE, ISI WEB OF KNOWLEDGE, HIGHWIRE STANFORD UNIVERSITY, SCIENCE DIRECT, WILEY - BLACKWELL, OXFORD JOURNALS, SAGE JOURNALS, CAMBRIDGE JOURNALS E EMERALD.

c) busca dos artigos nos bancos de dados com as palavras-chave:

Concluída a busca das seis palavras-chave nas 11 bases de dados selecionadas, considerando os filtros definidos pelos autores, foram selecionadas 6.438 publicações que passaram a compor um portfólio inicial denominado Banco de Artigos Brutos.

d) realização de teste de aderência das palavras-chave: 
Finalizando a seleção do Banco de Artigos Brutos, foi realizado teste para verificar a aderência das palavras-chave diante dos artigos selecionados. Para a realização do teste de aderência foram selecionados, aleatoriamente, dois artigos dentre as 6.438 publicações que compõe o Banco de Artigos Bruto. Foram identificadas as palavras-chave de cada um dos artigos selecionados, sendo verificado se estas palavras-chave coincidiam com aquelas definidas para a pesquisa. Como resultado do teste, ficou evidenciado que, das 16 palavras-chave pertencentes aos dois artigos, cinco encontravam-se listadas entre as seis palavras-chave definidas para a pesquisa.

\subsubsection{Filtragem do Bando de Artigos Brutos}

$\mathrm{Na}$ etapa de filtragem do Bando de Artigos Brutos os 6.438 artigos do Banco de Artigos Brutos foram analisados quanto aos seguintes aspectos: i) se os artigos não estão repetidos (redundância); ii) se os títulos dos artigos estão alinhados com o tema da pesquisa; iii) se os artigos possuem reconhecimento científico; iv) se os resumos dos artigos estão alinhados com o tema da pesquisa; e v) se o texto integral dos artigos está alinhado com o tema da pesquisa.

As publicações selecionadas nas bases de dados pesquisadas foram importadas para uma única biblioteca virtual, utilizando-se a ferramenta EndNote. Importadas as publicações, foi identificado que, apesar dos filtros aplicados durante a busca, o Banco de Artigos Brutos possuía 456 publicações que não eram artigos. Com a eliminação destas publicações restaram 5.982 artigos. Na análise de redundância foram identificados e removidos 1.575 artigos duplicados, restando 4.407 artigos no Banco de Artigos Brutos

$\mathrm{Na}$ análise quanto ao alinhamento do título em relação ao tema da pesquisa, foi detectado que uma quantidade considerável de artigos selecionados estava direcionada à área da medicina, portanto, estando fora do escopo da pesquisa, sendo removidos 4.317 artigos. Restaram 90 artigos não duplicados e com o título alinhado ao tema da pesquisa, que foram submetidos à análise quanto ao reconhecimento acadêmico, ou seja, foram verificadas quantas vezes cada um dos artigos foi citado no Google Scholar. Foram selecionados para continuarem fazendo parte do Banco de Artigos Brutos os artigos que tiveram ao menos uma citação, ou seja, 41 artigos, que foram então submetidos à análise do alinhamento do resumo em relação ao tema da pesquisa. Restaram 18 artigos não duplicados, com reconhecimento científico e com título e resumo alinhado ao tema da pesquisa.

Os demais 49 artigos não foram rejeitados, para não descartar autores relevantes que, por terem publicado recentemente seus trabalhos, ainda não tiveram número considerável de citações. Em um processo de repescagem, verificou-se que 24 artigos foram publicados recentemente (nos anos de 2009, 2010 e 2011) possuindo potencial para reconhecimento científico futuro. Ficou evidenciado ainda que, dentre os 
25 artigos rejeitados em razão da falta de reconhecimento científico e publicados a mais de dois anos, dois artigos haviam sido publicados por autores que constam dentre os autores dos 18 artigos com reconhecimento científico e título e resumo alinhado com o tema da pesquisa. Os 24 artigos com publicação recente e os dois artigos com autor relevante no contexto da pesquisa, foram submetidos à análise do alinhamento do resumo em relação ao tema da pesquisa, restando desta análise três artigos com resumo alinhado, que foram incorporados aos 18 artigos com reconhecimento científico e título/resumo alinhados, obtendose um Banco de Artigos Não Repetidos, com Título e Resumo Alinhados e com Reconhecimento Científico composto por 21 artigos.

Finalizando a etapa de filtragem do Banco de Artigos Brutos, os 21 artigos selecionados foram analisados em relação ao alinhamento do texto integral com o tema da pesquisa. Dos 21 artigos, cinco não possuíam texto completo disponível no portal da CAPES, restando 16 artigos, que, após análise quanto ao alinhamento do texto completo em relação ao tema da pesquisa, foram reduzidos a 14 artigos com alinhamento do texto completo com o tema da pesquisa. O processo de filtragem resultou em um Portfólio Bibliográfico formado pelos 14 artigos, listados no Quadro 1.

Quadro 1 - Portfólio final de artigos

\section{Portfólio Bibliográfico}

1. AVEN, T. A unified framework for risk and vulnerability analysis covering both safety and security. Reliability Engineering and System Safety, v. 92, n. 6, p. 745-754, 2007.

2. BAKER III, T. A.et al. Perceived Risk of Terrorism and Related Risk Management Practices of NCAA Division 1A Football Stadium Managers. Journal of Legal Aspects of Sport, v. 17, n. 1, p. 27-51, Winter 2007.

3. BROCKLEHURST, D. et al. Crowd circulation and stadium design: low flow rate systems. Proceedings of the Institution of Civil Engineers-Structures and Buildings, v. 158, n. 5, p. 281289, Oct. 2005.

4. FROSDICK, S. Policing, safety and security in public assembly facilities. International Journal of Police Science \& Management: Vathek Publishing Ltd. v. 12, p. 81-89, 2010.

5. GIULIANOTTI, R.; F. KLAUSER. Security governance and sport mega-events: Toward an interdisciplinary research agenda. Journal of Sport and Social Issues, v. 34, n. 1, p. 49-61, 2010.

6. HALL, S. et al. Introducing a risk assessment model for sport venues. Sport Journal, v. 10, n. 2, p. 8, 2007.

7. HALL, S. et al. Spectator perceptions of security management at a NASCAR (National Association for Stock Car Auto Racing) event. Sport Journal, v. 12, n. 1, p. 6, Winter 2009.

8. HALL, S. A. An examination of British sport security strategies, legislation, and risk management practices. Sport Journal, v. 13, n. 2, p. 3-3, 2010.

9. HOLLNAGEL, E. Risk + barriers = safety? Safety Science, v. 46, n. 2, p. 221-229, 2008

10. JOHNES, M. 'Heads in the sand': football, politics and crowd disasters in twentieth-century Britain. Soccer \& Society, v. 5, n. 2, p. 134-151, Summer 2004.

11. PIWOWAR, J. et al. An efficient process to reduce infrastructure vulnerabilities facing malevolence. Reliability Engineering \& System Safety, v. 94, n. 11, p. 1869-1877, 2009.

12. SAHINOGLU, M. Security meter: a practical decision-tree model to quantify risk. IEEE Security and Privacy, v. 3, n. 3, p. 18-24, 2005.

13. STEVEN, H. A. et al. Management of Sports Facilities: Stress and Terrorism Since 9/11. Management Research News, v. 28, n. 7, p. 69-83, 2005.

14. WARREN, A. W. Using biometrics for sport venue management in a post 9-11 era. Facilities, v. 21, n. $5 / 6$, p. $134-141,2003$.

Fonte: Autores (2011). 


\subsection{Análise Bibliométrica}

O subprocesso de análise bibliométrica do Portfólio Bibliográfico consiste na aplicação de métodos estatísticos e matemáticos (DA FONSECA, 1973) sobre os artigos selecionados, para quantificar as informações existentes e mapear a estrutura do conhecimento de um campo científico, servindo, também, como uma ferramenta de análise do comportamento dos pesquisadores em suas decisões na construção desse conhecimento (PRITCHARD, 1969; CALDAS; TINOCO, 2004; BUFREM; PRATES, 2005).

A análise bibliométrica do Portfólio Bibliográfico selecionado para a presente pesquisa foi desenvolvida em quatro etapas: i) estimar o grau de relevância dos periódicos; ii) estimar o reconhecimento científico dos artigos; iii) estimar o grau de relevância dos autores; e iv) estimar as palavras-chave mais utilizadas (LACERDA et al., 2011; AFONSO et al., 2011; AZEVEDO et al., 2011; ROSA et al, 2011; LACERDA et al., 2012; ROSA et al., 2012).

Em cada uma das etapas, a exceção da estimativa das palavraschave mais utilizadas, as análises serão realizadas na seguinte ordem: i) análise bibliométrica dos artigos do Portfólio Bibliográfico; ii) análise bibliométrica das referências dos artigos do Portfólio Bibliográfico; e iii) Análise bibliométrica do conjunto formado pelos artigos e suas referências.

Preliminarmente à aplicação da análise bibliométrica, foi definido o conjunto de dados a serem submetidos à análise, composto por 14 artigos que formam o Portfólio Bibliográfico selecionado para a pesquisa e pelas 92 referências bibliográficas do tipo Journal Article encontradas nos artigos do Portfólio Bibliográfico.

\subsubsection{Estimar o grau de relevância dos periódicos}

A primeira análise realizada busca identificar em qual periódico foi publicado o maior número de artigos dentre os que compõem o Portfólio Bibliográfico. Os artigos do Portfólio Bibliográfico foram publicados em 11 periódicos diferentes, ficando evidenciado que o periódico "Sport Journal" é o que apresenta maior grau de relevância, com três artigos publicados.

A segunda análise busca identificar em qual periódico foi publicado o maior número de artigos dentre os citados nas referências do Portfólio Bibliográfico. As referências dos artigos do Portfólio Bibliográfico foram publicadas em 72 periódicos diferentes, evidenciando que os periódicos "Reliability Engineering and System Safety" e "Sociological Review" foram os que apresentaram maior grau de relevância, com cinco publicações cada.

A terceira análise compara a relevância dos periódicos dos artigos do Portfólio Bibliográficos e a relevância dos periódicos das referências do Portfólio Bibliográfico, ficando evidenciado que: i) nenhum dos periódicos apresenta destaque, ao mesmo tempo, nos artigos do Portfólio Bibliográfico e nas suas referências; ii) o periódico "Sport Journal" 
apresenta destaque no Portfólio Bibliográfico; e iii) o periódico "Reliability Engineering and System Safety" apresenta destaque nas referências do Portfólio Bibliográfico. Estes resultados estão demonstrados na Figura 3.

Figura 3 - Relevância dos periódicos presentes nos artigos e nas referências da pesquisa

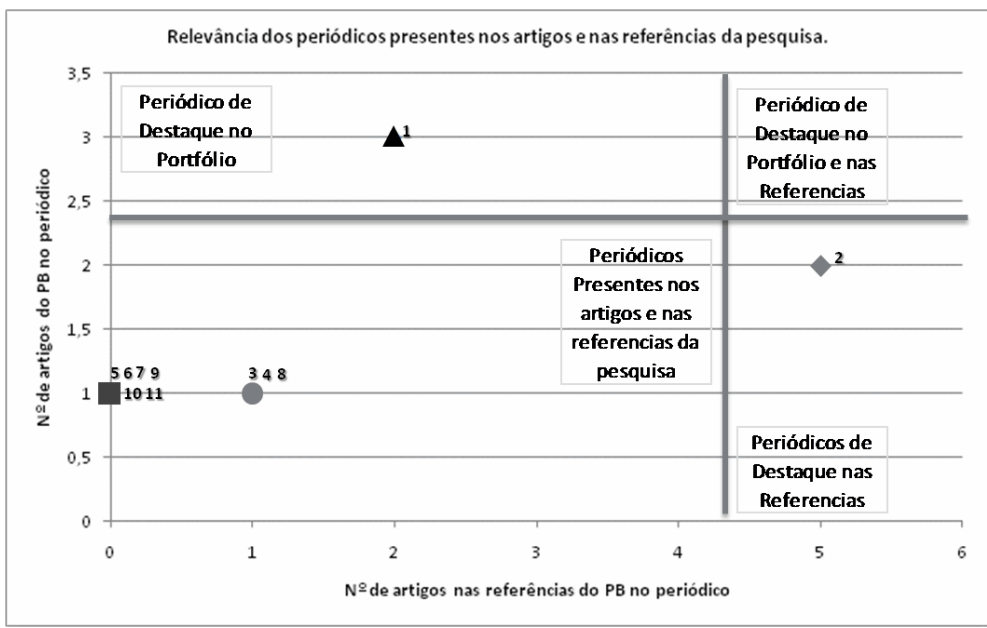

PERIÓDICOS

1. Sportlournal . Reliability Engineering \& System Safet/ 4. FEEF Security and Privacy 5. International Journal of 6. Journal of Legal Aspects of 5 port 7. Journal of Sport and Social Issue - Mroceedings of the Institution of $c$ -10. Safety Science 11. Soccer \& Society

Fonte: Autores (2011)

\subsubsection{Estimar o grau de reconhecimento científico dos artigos}

Para fins desta análise, entende-se reconhecimento científico de um artigo como sendo o número de citações encontrados para o artigo após consulta ao Google Scholar.

A primeira análise realizada busca estimar o reconhecimento científico dos artigos do Portfólio Bibliográfico, restando evidenciado como de maior relevância o artigo de Sahinoglu (2005).

A segunda análise busca avaliar o reconhecimento científico dos artigos do Portfólio Bibliográfico nas referências presentes nos artigos do Portfólio Bibliográfico, evidenciado que apenas dois artigos do Portfólio Bibliográfico foram citados nas referências do Portfólio Bibliográfico, cada qual com uma citação: Steven et al. (2005) e Warren (2003).

A terceira análise compara o número de citações do artigo do Portfólio Bibliográfico e o número de citações obtidas pelo autor mais citado de cada um dos artigos nas referências do Portfólio Bibliográfico, com base no Google Scholar, evidenciando que: i) nenhum artigo de destaque do Portfólio Bibliográfico foi realizado por autor de destaque das referências do Portfólio Bibliográfico; ii) os artigos de Sahinoglu (2005) e Aven (2007) apresentam destaque no Portfólio Bibliográfico; e iii) o artigo de Steven et al. (2005) foi realizado por autor de destaque nas referências do Portfólio Bibliográfico. Os resultados desta análise podem ser observados na Figura 4. 
Figura 4 - Artigos e seus autores do Portfólio Bibliográfico de maior destaque

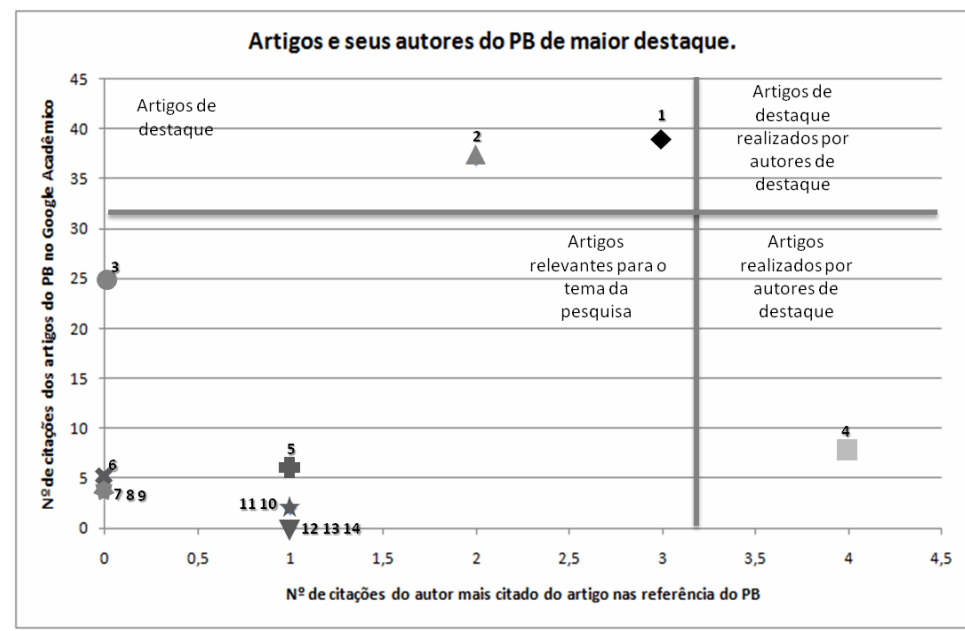

ARTIGOSDOPB

-1. Security meter: A practical decision-tree ...

3. Risk + barriers $=$ safety?

5. Using biometrics for sport venue

6. . Heads in the sand': foo thall, politics and

7. Crowd circulation and stadium design:....

9. Perceived Risk of Terrorism and Related Risk.

10. Introducing a risk assessment model for... 12. An Examination of British Sport Security... 13. Policing, safety and security in public

Fonte: Autores (2011).

\subsubsection{Estimar o grau de relevância dos autores}

A primeira análise realizada busca evidenciar quais os autores de maior destaque dentre os 28 autores dos artigos do Portfólio Bibliográfico, apresentando que o autor de maior relevância foi Stacey A. Hall, com três artigos publicados.

A segunda análise realizada busca evidenciar quais os autores de maior relevância dentre os 181 autores das referências dos artigos do Portfólio Bibliográfico, mostrando que o autor de maior relevância foi Steven $\mathrm{H}$. Appelbaum, com quatro artigos publicados.

A terceira análise compara o número de artigos realizados pelos autores do Portfólio Bibliográfico e o número de artigos de cada autor nas referências do Portfólio Bibliográfico, evidenciando que: i) não existe nenhum autor que seja destaque ao mesmo tempo no Portfólio Bibliográfico e nas referências do Portfólio Bibliográfico; ii) o autor de maior destaque nas referências do Portfólio Bibliográfico foi Steven $\mathrm{H}$. Appelbaum; e iii) o autor de maior destaque nos artigos do Portfólio Bibliográfico foi Stacey A. Hall. Os resultados obtidos com esta análise estão demonstrados na Figura 5. 
Figura 5 - Autores de destaque do Portfólio Bibliográfico
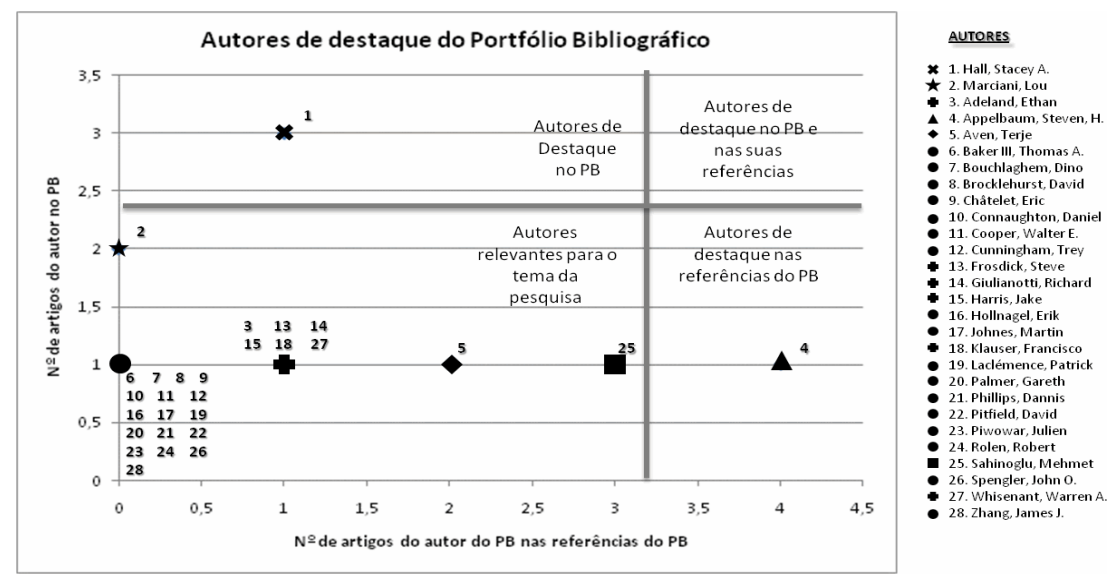

Fonte: Autores (2011).

\subsubsection{Estimar as palavras-chaves mais utilizadas}

A análise realizada buscou identificar quais as palavras-chave mais utilizadas nos artigos do Portfólio Bibliográfico. Foram identificadas 86 palavras-chave, utilizadas 114 vezes nos artigos do Portfólio Bibliográfico. Do total das palavras-chave, 18 foram utilizadas duas vezes ou mais, sendo que a palavra-chave mais utilizada (RISK ASSESSMENT) apareceu cinco vezes no Portfólio Bibliográfico.

Além da análise quanto à frequência de utilização das palavraschave, foi realizada comparação entre as palavras-chave definidas para o tema da pesquisa e aquelas do Portfólio Bibliográfico. Nesta análise, buscou-se identificar quais as palavras-chave definidas para o tema da pesquisa estavam presentes nas palavras-chave do Portfólio Bibliográfico. Evidenciou-se que quatro das seis palavras-chave definidas para o tema da pesquisa foram encontradas, dentre aquelas do Portfólio Bibliográfico utilizadas duas vezes ou mais.

\section{Considerações finais}

Através deste artigo, procurou-se analisar a questão da gestão de risco em estádios de futebol profissional, voltada para a segurança das pessoas que participam dos espetáculos futebolísticos, objetivando identificar, na literatura internacional, quais os principais artigos existentes sobre o tema, com reconhecimento científico; quem são os pesquisadores que estão tratando do tema; quais os periódicos mais relevantes; e quais as palavras-chave mais utilizadas. 
O futebol, enquanto esporte de massa, possui um lado lúdico que traz espetáculo e alegria. Porém, em função da paixão que move alguns torcedores, associada a questões relativas às instalações físicas dos estádios onde é praticado, ocorrem tumultos e conflitos, resultando, muitas vezes, em morte de pessoas.

As autoridades tem procurado implementar ações no sentido de reduzir os riscos, dentre as quais está a avaliação periódica das instalações físicas dos estádios, porém, o processo carece de cientificidade.

Neste artigo, procurou-se, através do processo ProKnow-C (Knowledge Development Process - Constructivist), construir, no pesquisador, o conhecimento sobre o que já foi publicado acerca do tema "Gestão de Risco em Estádios de Futebol". O conhecimento construído, embora de forma parcial, permitirá que o pesquisador, em um momento seguinte, pesquise as oportunidades (lacunas) existentes, complementando o conhecimento sobre o tema pesquisado.

A aplicação do processo ProKnow-C (Knowledge Development Process - Constructivist) compreendeu a seleção do Portfólio Bibliográfico, com base na literatura internacional sobre o tema, e a Análise Bibliométrica dos artigos selecionados.

A etapa de Seleção do Portfólio Bibliográfico iniciou-se com a pesquisa das seis palavras chave nas 11 bases de dados selecionadas, resultando em um Banco de Artigos Bruto composto por 6.438 publicações. O Banco de Artigos Bruto foi então submetido a um processo de filtragem quanto à redundância dos artigos, quanto ao reconhecimento científico e quanto ao alinhamento do título, resumo e texto integral.

Findo o processo de Seleção do Portfólio Bibliográfico para o tema "Gestão de Risco em Estádios de Futebol", analisado segundo a perspectiva dos pesquisadores, obteve-se como resultado um Portfólio Bibliográfico composto por 14 artigos, apresentados no Quadro 1.

Após a seleção do Portfólio Bibliográfico foi realizada a análise bibliométrica. Nessa análise, buscou-se evidenciar quais os periódicos, artigos, autores e palavras-chave de destaque nos artigos do Portfólio Bibliográfico, bem como nas referências presentes em cada um destes artigos.

Da análise do grau de relevância dos periódicos onde foram publicados os artigos do Portfólio Bibliográfico e as suas referências, evidenciou-se que nenhum dos periódicos apresenta destaque, ao mesmo tempo, nos artigos do Portfólio Bibliográfico e nas suas referências. 0 periódico "Sport Journal" apresenta destaque nos artigos do Portfólio Bibliográfico, enquanto o periódico "Reliability Engineering and System Safety" possui maior destaque nas referências do Portfólio Bibliográfico, conforme demonstrado na Figura 3.

A análise quanto ao reconhecimento científico dos artigos, realizada por meio da verificação do número de citações que cada artigo obteve no Google Acadêmico, evidenciou que nenhum artigo de destaque do Portfólio Bibliográfico foi realizado por autor de destaque das referências do Portfólio Bibliográfico, conforme demonstrado na Figura 4. Os artigos 
de Sahinoglu (2005) e Aven (2007) apresentam destaque no Portfólio Bibliográfico, enquanto o artigo de Steven et al.(2005) apresenta destaque nas referências dos artigos do Portfólio Bibliográfico.

Quanto aos autores de destaque no Portfólio Bibliográfico e nas suas referências, desta análise, mostrou-se que não existe nenhum autor que seja destaque ao mesmo tempo no Portfólio Bibliográfico e nas suas referências, conforme demonstrado na Figura 5. Evidenciou-se, também, que o autor de maior destaque nas referências do Portfólio Bibliográfico foi Steven $H$. Appelbaum, e o autor de maior destaque nos artigos do Portfólio Bibliográfico foi Stacey A. Hall.

Finalizando a análise bibliométrica, foi realizada a contagem das palavras-chave mais utilizadas, restando evidenciado que das seis palavras-chave definidas para o tema da pesquisa quatro foram encontradas dentre as palavras-chave do Portfólio Bibliográfico utilizadas duas vezes ou mais, sendo as mais utilizadas: risk assessment, security systems e risk management.

O conhecimento construído permitiu aos pesquisadores conhecerem: i) um portfólio de artigos com reconhecimento científico e alinhado com seus interesses no tema; ii) quem está pesquisando; iii) quais periódicos estão publicando; e iv) quais as palavras-chave estão sendo as mais utilizadas.

A pesquisa foi delimitada com base na visão de mundo dos pesquisadores, estando restrita a: i) artigos publicados em periódicos científicos indexados a base de dados disponíveis gratuitamente no portal de periódicos da CAPES; ii) artigos publicados em periódicos internacionais; iii) artigos do tipo "Journal Article", não sendo consideradas outras fontes de pesquisa, tais como: livros, dissertações e teses; e iv) artigos publicados entre os anos de 2001 a 2010.

Futuras pesquisas podem vir a ser aplicadas ao conteúdo identificado no presente trabalho, especialmente no que se refere à realização de Análise Sistêmica, o que permitirá identificar possíveis lacunas existentes na literatura, em relação à temática da gestão de risco em estádios de futebol.

\section{Referências}

AFONSO, M. H. F. et al., Como construir conhecimento sobre o tema de pesquisa? Aplicação do processo Proknow-C na busca de literature sobre avaliação do desenvolvimento sustentável. Revista de Gestão Social e Ambiental, v. 5, n. 2, p. 47-62, mai./ago, 2011.

ALAVI, M.; CARLSON, P. A review of MIS research and disciplinary development. Journal of Management Information Systems, v. 8, n. 4, p. 45-62, 1992.

AVEN, T. A unified framework for risk and vulnerability analysis covering both safety and security. Reliability Engineering and System Safety, v. 92, n. 6, p. $745-754,2007$. 
AZEVEDO, R. C. et al. Avaliação de desempenho do processo de orçamento: estudo de caso em uma obra de construção civil. Ambiente Construído, v. 11, p. 85-104, 2011.

BUFREM, L.; PRATES, Y. O saber científico registrado e as práticas de mensuração da informação. Ciência da Informação, Brasília, DF, n. 34, mar. $2006 . \quad$ Disponível em: <http://revista.ibict.br/index.php/ciinf/article/view/682/586>. Acesso em: 20 abr. 2011.

BORTOLUZZI, S. C. et al. A Avaliação de desempenho em redes de pequenas e médias empresas: estado da arte para as delimitações postas pelo pesquisador. Revista Eletrônica de Estratégia \& Negócios, Florianópolis, v. 4, n. 2, p. 202-222, jun./dez.2011.

CALDAS, M. P.; TINOCO, T. Pesquisa em gestão de recursos humanos nos anos 1990: um estudo bibliométrico. Revista de administração de empresas, São Paulo, v. 44, n. 3, set. 2004. Disponível em <http://www.scielo.br/scielo.php?script=sci_arttext\&pid=S0034-7590 $2004000300008 \&$ Ing =pt\&nrm=iso >. Acesso em: 15 maio 2011.

DA FONSECA, E. Bibliografia estatística e bibliometria: uma reivindicação de prioridades. Ciência da Informação, Brasília, DF, v. 2, n. 1, p. 5-7, 2, jun. $1973 . \quad$ Disponível em: <http://revista.ibict.br/index.php/ciinf/article/view/1625/1234>. Acesso em: 23 abr. 2011.

DECKER, R. Homeland security: key elements of a risk management approach. Washington, D.C.: United States General Accounting Office, October 12 2001. (Open-file report: GAO-02-150T).

DE MORAES, L. et al. The multicirteria analysis for construction of bench markers to support the Clinical Engineering in the Healthcare Technology Management. European Journal os Operational Research, v.200, p. 607615, 2012.

DUTRA, A.; ENSSLIN, L.; ENSSLIN, S. R. A constructivist approach to the management of human resources at a governanmental agency. International Transactions in Operational Research - IFORS, v. 7, p.79$100,2000$.

ENSSLIN, L. et al. Identificando e analisando problemas de performance: o uso da avaliação de desempenho (Feedback, Coaching e Counseling) para melhorar a produtividade dos empregados. Florianópolis: UFSC, 2007.

ENSSLIN, L. Material didático apresentado na disciplina: avaliação de desempenho do Programa de Pós-graduação em Engenharia de Produção da Universidade Federal de Santa Catarina. Florianópolis: UFSC, 2011.

ENSSLIN, L. et al. ProKnow-C, Knowledge Development Process Constructivist: processo técnico com patente de registro pendente junto ao INPI. Brasil: [s.n.], 2010a. 
ENSSLIN, L. et al. Avaliação do desempenho de empresas terceirizadas com o uso da metodologia multicritério de apoio à decisão- construtivista. Revista Pesquisa Operacional, v. 30, n. 1, p. 125-152, Jan./Abr. 2010b.

FERREIRA, N. S; YOSHIDA, E. M. P. Produção científica sobre psicoterapias breves no Brasil e demais países latino-americanos (19902000). Est. Psicol., Natal, v. 3, n. 3, p. 523-531, set./dez. 2004.

GIL, A. C. Métodos e técnicas de pesquisa social. São Paulo: Atlas, 1999.

HALL, S., L. et al. Introducing a risk assessment model for sport venues. Sport Journal, v. 10, n. 2, p. 8, 2007.

IGARASHI, D. C. C.; PALADINI, E. P.; ENSSLIN, S. R.. A metodologia multicritério de apoio à decisão construtivista como subsídio para o gerenciamento interno: estudo de caso do PPGC/UFSC. Organizações \& Sociedade, Brasília, DF, v. 14, n. 42, p. 133-149, jul-set, 2007. Disponível em: <http://www.revistaoes.ufba.br/viewarticle.php?id=175>. Acesso em: maio 2011.

IUDICIBUS, S. Teoria da contabilidade. São Paulo: Atlas, 2004.

JOHNES, M. 'Heads in the sand': football, politics and crowd disasters in twentieth-century Britain. Soccer \& Society, v. 5, n. 2, p. 134-151, Summer 2004.

LACERDA, R. T. O.; ENSSLIN, L.; ENSSLIN, S. R. Uma análise bibliométrica da literatura sobre estratégia e avaliação de desempenho. Gestão \& Produção, v 19, n.1, 2012.

LACERDA, R. T. O.; ENSSLIN, L.; ENSSLIN, S. R. Contribuições À gestão estratégica de organizações quando analisados na visão de seu desempenho. Gestão Organizacional, v. 9, n. 2, 2011.

LAKATOS, E. M.; MARCONI, M. A. Fundamentos de metodologia científica. 6. ed. São Paulo: Atlas, 2006.

MURPHY, P.; WILLIAMS, J.; DUNNING, E. O futebol no banco dos réus. Oeiras: Celta, 1994.

PRITCHARD, A. Statistical bibliography or bibliometricas. Journal of Documentation, v. 25, p. 348-349, 1969.

REIS, H. B. La relación entre fútbol, violencia y sociedad: un análisis histórico a partir de la teoría del proceso civilizador. Sevilla: [s.n.], 2005. Disponível em: < http://cafyd.com/HistDeporte/htm/pdf/4-15.pdf>. Acesso em: 13 maio 2011.

RICHARDSON, R. J. Pesquisa social: métodos e técnicas. São Paulo: Atlas, 1999.

ROSA, F.S. da et al. Management environmental discloure: a constructivis case. Management Decision, 2012. In press. 
ROSA, F.S. da et al. Gestão da evidenciação ambiental: um estudo sobre as potencialidades e oportunidades do tema. Engenharia Sanitária e Ambiental., v. 16, n. 2, p. 157-166, abr./jun. 2011.

SÁ-SILVA, J. R.; ALMEIDA, C. D.; GUINDANI, J. F. Pesquisa documental: pistas teóricas e metodológicas. Revista Brasileira de História \& Ciências Sociais, n. 1, 2009.

SAHINOGLU, M. Security meter: a practical decision-tree model to quantify risk. IEEE Security and Privacy, v. 3, n. 3, p. 18-24, 2005.

STEVEN, H. A. et al., Management of Sports Facilities: Stress and Terrorism Since 9/11. Management Research News, v. 28, n. 7, p. 69-83, 2005.

TASCA, J. et al. An approach for selecting a theoretical framework for the evaluation of training programs. Journal of European Industrial Training, v. 34, p. 631-655, 2010.

VIEIRA, V. A. As tipologias, variações e características da pesquisa de marketing. Revista $F A E$, v. 5, n. 1, p. 61-70, jan./abr. 2002.

WARREN, A. W. Using biometrics for sport venue management in a post 911 era. Facilities, v. 21, n. 5/6, p.134-141. 2003.

ZAMCOPE, F. C. et al. Modelo para avaliar o desempenho de operadores logísticos: um estudo de caso na indústria têxtil. Gestão \& Produção, São Carlos, v. 17, n. 4, dez. 2010 . Disponível em $<$ http://www.scielo.br/scielo.php?script=sci_arttext\&pid=S0104$530 \times 2010000400005 \& \mid n g=$ pt $\& \mathrm{nrm}=$ iso $>$. Acesso em: 15 maio 2011. 